\title{
A AUDIODESCRIÇÃO NA DANÇA EM CADEIRA DE RODAS
}

\author{
The audiodescription in wheelchair dance
}

\author{
La audiodescripción en la danza en silla de ruedas
}

\author{
Luciene Rodrigues Fernandes* \\ Evanize Kelli Siviero Romarco* \\ Lívia Fabiana Saço* \\ Eliana Lucia Ferreira*
}

\begin{abstract}
Resumo
O estudo teve como objetivo elaborar um roteiro de Audiodescrição (AD) de um espetáculo de dança em cadeira de rodas (DECR); e verificar a significância e viabilidade deste recurso, quanto a compreensão da descrição dos movimentos, por pessoas com deficiência visual e profissionais na área da dança. Trata-se de uma pesquisa descritiva e exploratória ao qual foi construído e apresentado o roteiro da $\mathrm{AD}$ do espetáculo de dança em cadeira de rodas. O roteiro foi aplicado em um software de legendagem Workshop (SW), versão 2.51 e a $\mathrm{AD}$ da dança em cadeira de rodas foi apreciada pelos participantes da pesquisa. Como instrumento de coleta de dados todos responderam a um questionário sobre os significados/entendimento da coreografia somado a uma entrevista quanto a compreensão dos gestos corporais narrados na $\mathrm{AD}$. As respostas foram comparadas entre si buscando identificar as concordâncias e discrepâncias assinaladas pelos participantes. Pelos resultados podemos analisar que este estudo trouxe contribuições expressivas, sistematizando termos referentes à dança em cadeira de rodas no estilo Rumba, permitindo que esta modalidade de dança seja acessível ao deficiente visual em futuras competições nacionais e internacionais.
\end{abstract}

PALAVRAS-CHAVE: Acessibilidade. Audiodescrição. Dança em Cadeira de Rodas

\begin{abstract}
The purpose of this study was to elaborate an Audiodescription (AD) script of a wheelchair dance show (DECR); and to verify the significance and viability of this resource, as well as the understanding of the description of the movements by people with visual and professional disabilities in the dance area. It is a descriptive and exploratory research to which the AD script of the wheelchair dance show was constructed and presented. The script was applied in a Workshop (SW) subtitling software, version 2.51 and the $\mathrm{AD}$ of wheelchair dancing was appreciated by the participants of the

\footnotetext{
* Docente na Fundação Centro Integrado de Apoio a Pessoa Deficiente (FUNAD). Pós-graduação em Esportes e atividades físicas inclusivas para pessoas com deficiência Universidade Federal de Juiz de Fora (UFJF). Pós graduação em Audiodescrição pela Universidade Federal de Juiz de Fora (UFJF). Membro do grupo de estudos NGIME/UFJF.

* Docente na Universidade Federal de Viçosa. Doutora em Dança e Educação Somática pela Faculdade de Motricidade Humana - Universidade de Lisboa-PT. Email: eva_siviero@ufv.br

* Mestre em Educação Física pela Universidade Federal de Juiz de Fora (UFJF). Membro do grupo de estudos NGIME/UFJF. Técnico em assuntos educacionais - Fisioterapeuta - UFJF. Email: livia.saco@ufjf.edu.br.

* Docente do programa de Educação Física da Universidade Federal de Juiz de Fora (UFJF). Pós-doutorado em Avaliação Educacional do Ensino pela Universidade Nacional do Ensino a distância - UNED-Espanha. Líder do grupo de pesquisa NGIME/UFJF. Email: eliana.ferreira@ufjf.edu.br.
}

Educação e Fronteiras On-Line, Dourados/MS, v.10, n.28, p.138-149, jan./abr. 2020 
research. As an instrument of data collection, all answered a questionnaire about the meanings / understanding of the choreography added to an interview regarding the comprehension of the body gestures narrated in the AD. The answers were compared among themselves to identify the concordances and discrepancies indicated by the participants. From the results we can analyze that this study has made expressive contributions, systematizing terms referring to the Rumba style wheelchair dance, allowing this dance modality to be accessible to the visually impaired in future national and international competitions

KEYWORDS: Accessibility. Audiodescription. Dance in Wheelchair

\section{Resumen}

El estudio tuvo como objetivo elaborar un guión de Audiodescripción (AD) de un espectáculo de danza en silla de ruedas (DECR); y verificar la significancia y viabilidad de este recurso, en cuanto a la comprensión de la descripción de los movimientos, por personas con discapacidad visual y profesionales en el área de la danza. Se trata de una investigación descriptiva y exploratoria al que fue construido y presentado el guión de la $\mathrm{AD}$ del espectáculo de danza en silla de ruedas. El guión fue aplicado en un software de subtitulado Workshop (SW), versión 2.51 y AD de la danza en silla de ruedas fue apreciado por los participantes de la investigación. Como instrumento de recolección de datos todos respondieron a un cuestionario sobre los significados / entendimiento de la coreografía sumado a una entrevista en cuanto a la comprensión de los gestos corporales narrados en la AD. Las respuestas fueron comparadas entre sí buscando identificar las concordancias y discrepancias señaladas por los participantes. Por los resultados podemos analizar que este estudio trajo contribuciones expresivas, sistematizando términos referentes la danza en silla de ruedas en el estilo Rumba, permitiendo que la modalidad de danza sea accesible al deficiente visual en futuras competiciones nacionales e internacionales.

PALABRAS ClAVE: Accesibilidad. Descripción de Audio. Danza en Silla de Ruedas

\section{INTRODUÇÃO}

As reivindicações de pessoas com deficiência visual na sociedade, nos mais diversos segmentos têm gerado ao longo dos tempos avanços para a resolução do problema comunicacional (ANJOS 2010). Pensando na acessibilidade, a Audiodescrição (AD) é um recurso que compactua com tal crescimento, principalmente, relacionada as atividades culturais objetiva a tradução de imagens em palavras, no qual elementos visuais de produções audiovisuais podem ser descritos e tornar-se compreensivos para as pessoas com deficiência visual. É um recurso que pode auxiliar não somente o cego, mas também, pessoas com deficiência intelectual, idosos, disléxicos, autistas, com déficit de atenção entre outros, para o entendimento em eventos culturais ao vivo e/ou gravados, eventos turísticos esportivos, pedagógicos e científicos por meio de informação sonora (MOTTA; ROMEU FILHO 2010). Pensando em um campo artístico e esportivo, também, pouco divulgado, na mídia e apreciado pela sociedade, a Dança em Cadeira de Rodas (DECR) está além de um repertório de passos e técnicas existentes nas diversas modalidades de dança, pois ela pressupõe uma certa especificidade na execução do movimento, devido as particularidades de cada dançarino (FERREIRA, 2009).

Sendo assim, para decifrar a dança em cadeira de rodas, é importante construir narrativas capazes de mostrar um maior número de gestos contidos nas expressões e nos 
diálogos realizados pela linguagem do corpo, diálogo esse, que por sua vez possibilita criar novas propostas de compreensão desta.

Diante disso, visamos por meio deste trabalho introduzir a AD na dança em cadeira de rodas com a proposta em proporcionar um maior acesso a participação de pessoas com deficiência visual, nesta arte produzida por/com pessoas com deficiência física. Através da elaboração de um roteiro de $\mathrm{AD}$ de um espetáculo de dança em cadeira de rodas - estilo rumba; e verificar a significância e viabilidade deste recurso, quanto a compreensão da descrição das imagens, por pessoas com deficiência visual e profissionais na área da dança.

\section{Deficiência Visual: acessibilidade, cidadania e inclusão social}

A deficiência visual se refere ao espectro que vai da cegueira até a visão subnormal. Segundo dados do IBGE (2010), no Brasil, das mais de 6,5 milhões de pessoas com alguma deficiência visual: 528.624 pessoas são incapazes de enxergar (cegos); 6.056.654 pessoas possuem baixa visão ou visão subnormal (grande e permanente dificuldade de enxergar). $\mathrm{O}$ indivíduo que nasce com o sentido da visão e vai perdendo progressivamente, guarda memórias visuais. Por outro lado, quem nasce sem a capacidade da visão, pode formar uma memória ou lembranças, por outros sistemas ou sentidos para apreender e se comunicar com os outros no espaço, principalmente em se tratando de sua orientação, mobilidade e autonomia.

Para Mendonça e colaboradores (2008, p. 67), as atividades de orientação e mobilidade têm como finalidade auxiliar o deficiente visual - cego ou com baixa visão - "[...] a construir o mapa cognitivo do espaço que o rodeia e deslocar-se nesse espaço, servindo-se para isso de um conjunto de técnicas apropriadas e específicas".

Hoffmann (1999) define orientação e mobilidade como um processo amplo e flexível, composto por um conjunto de habilidades motoras, cognitivas, sociais e emocionais e por um grupo de técnicas específicas (guia vidente ou cão guia, proteção e bengala), que possibilitam ao deficiente visual conhecer, relacionar-se e deslocar-se de forma independente e autônoma nas várias estruturas, nos espaços e nas situações do ambiente.

O domínio e o manejo dos recursos e técnicas de orientação e mobilidade oferecem à pessoa com deficiência visual a diversificação e a qualificação das experiências locomotoras e, por conseguinte, o exercício das habilidades motoras e cognitivas. Segundo Hoffmann (1999) essa atitude promove o autoconhecimento e o confronto diante das dificuldades, possibilitando o aumento da confiança e da segurança em sua potencialidade, bem como a constatação das limitações. Por isso, gradualmente, pode ocorrer à aquisição ou reconquista do sentimento de autoconfiança e posteriori a autonomia.

A autonomia, por exemplo, para ser adquirida, as informações devem ser transformadas em estímulos táteis e sonoros ou ainda aplicar recursos para essa compreensão e nesse contexto, a AD mostra-se como recurso por narrativas visuais de inclusão cultural, social e escolar para a pessoa com deficiência visual, recurso este que está sendo oferecido em algumas regiões do país (MOTTA; ROMEU FILHO, 2010).

A AD é uma realidade que vem acontecendo em países da Europa e Estados Unidos há aproximadamente 30 anos. Este instrumento de acessibilidade vem se destacando e ganhando espaços em vários locais à medida que as políticas públicas compreendem as necessidades e os direitos da pessoa com deficiência, pois as barreiras atitudinais podem levar 
à total exclusão de uma pessoa com deficiência, por exemplo, ao deixar de oferecer o contato acessível com acervos bibliográficos, programas artísticos e arquivos culturais socialmente construídos (FRANCO; SILVA, 2010).

No Brasil, com os avanços contínuos em prol da inclusão social, surge com a Lei $\mathrm{n}^{\circ}$ 10.098 de 19 de dezembro de 2000, que ficou conhecida como Lei da Acessibilidade, por estabelecer normas gerais e critérios básicos para a promoção da acessibilidade das pessoas com deficiência ou mobilidade reduzida, além de outras providencias. O artigo 17 desta lei merece ser aqui destacado, por ser aquele diretamente relacionados à AD:

\begin{abstract}
Art. 17. O Poder Público promoverá a eliminação de barreiras na comunicação e estabelecerá mecanismo e alternativas técnicas que tornem acessíveis os sistemas de comunicação e sinalização às pessoas portadoras de deficiência sensorial e com dificuldade de comunicação, para garantir-lhes o direito de acesso à informação, à comunicação, ao trabalho, à educação, ao transporte, à cultura, ao esporte e ao lazer. ${ }^{1}$
\end{abstract}

No entanto, o Ministério das Comunicações ciente da necessidade de se promover e implementar o acesso das pessoas com deficiência visual, aos meios de comunicação, bem como ao compartilhamento dos bens culturais socialmente produzidos, aprova somente em 27 de junho de 2006, a Portaria $N^{\circ} .310 / 2006$, a qual define, entre outros, a AD como um recurso de acessibilidade que: "[...] corresponde a uma locução, em língua portuguesa, sobreposta ao som original do programa, destinada a descrever imagens, sons, textos e demais informações que não poderiam ser percebidos ou compreendidos por pessoas com deficiência visual".

Mas apenas, em 30 de julho de 2008, a Portaria ${ }^{\circ} 466 / 2008$, determinou em seu artigo $1^{\circ}$. " $[. .$.$] conceder o prazo de noventa dias, contado da data de publicação desta Portaria, para$ que as exploradoras de serviço de radiodifusão de sons e imagens e de serviço de retransmissão de televisão (RTV) passem a veicular, na programação por elas exibidas, o recurso de acessibilidade".

Segundo Jakobson (1995) a AD por ser uma atividade de mediação linguística, acaba sendo uma modalidade de tradução conceituada como a intersemiótica, que transforma a informação visual em informação verbal (sonora); e proporciona às pessoas com deficiência visual o acesso ao conteúdo visual de produtos e eventos em que a plena compreensão dependa da descrição dessas imagens. O objetivo desse recurso, segundo Franco e Silva (2010) é simular o sentido da visão através da audição, para que informações importantes possam ser compreendidas.

No campo das ciências, no Brasil, a AD tem sido desenvolvida pelas universidades federais da Bahia, de Pernambuco, Minas Gerais e pela universidade estadual do Ceará. A formação de profissionais no Brasil, tem acontecido de duas formas distintas: a primeira por meio de cursos informais subsidiados pela iniciativa privada como destaque a professora Dra. Lívia Motta (FRANCO; SILVA, 2010), já o segundo modelo se dá a partir da formação universitária no nível de especialização ou extensão, o qual atualmente a Universidade Federal de Juiz de Fora (UFJF) representada pelas professoras: Dra. Eliana Lucia Ferreira e Dra. Lívia Motta. ${ }^{2}$

\footnotetext{
${ }^{1}$ Disponível em: https://www.planalto.gov.br/ ccivel_03/leisI10098.htmEM.Acesso em: 28 de abril de 2018.

${ }^{2}$ NGIME. Disponível em: <www.ngime.ufjf.br〉. Acesso em: 28 de abril de 2018.
} 
A inclusão da profissão audiodescritor, por exemplo, na CBO - Classificação Brasileira de Ocupações é tão recente que só foi realizada no dia 21 de fevereiro de 2013, com posterior regulamentação da profissão. Para Mazzotta (2005), quando existe obstáculo de acesso aos serviços sociais e culturais, há uma supressão à liberdade e a equidade nas relações sociais fundamentais à condição de ser humano. Acessibilidade não é somente a possibilidade de entrar em um ambiente, mas é o direito de participar ativamente no meio social. Trata-se de cidadania e inclusão social

Quanto a descrição na $\mathrm{AD}$, esta pode ser realizada de duas formas: a descrição ao vivo ou disponibilizada de forma gravada, em formato de vídeo ou áudio. Cada produção deve ser tratada de acordo com suas características. Para Benecke (2004, p. 78-80) alguns passos devem ser seguidos para elaboração de um roteiro de AD, são eles: 1) Escolha de programas adequados, pois nem todos correspondem a determinadas necessidades; 2) Preparação do roteiro; 3) Ensaio da locução e; 4) Ajustes do volume do som original, pela dificuldade dos deficientes visuais da compreensão da fala na presença de sons de fundo.

Estes mesmos autores apontam que a cultura é um instrumento facilitador para operar transformações na vida do indivíduo, principalmente a inclusão social, se comporta como um conjunto de formas simbólicas impregnadas nas pessoas e nos grupos. Sabemos que a mesma tem um papel relevante, no que diz respeito a oferecer possibilidades de transformações, sejam elas, ideológicas, comportamental ou material, trazendo autonomia para o deficiente visual. Dentre as possibilidades de autonomia, destacamos atividades como a dança, e os esportes como o: Atletismo; Futebol para cegos (ou de cinco); Goalball; Judô; Natação e a Dança em Cadeira de Rodas.

Segundo Ferreira (2009), a dança em cadeira de rodas representa uma ferramenta utilizada como forma de lazer, educação do movimento, terapia, esporte e como arte. Pode ser compreendida em diferentes aspectos como sua função social, seu caráter educativo, seu caráter performático, dentre outros. Nesse contexto, a dança em cadeira de rodas pode ser artística ou esportiva, sendo que na dança artística o indivíduo tem liberdade de expressar seus gestos corporais e sentimentos por meio das possibilidades técnicas disponíveis. Já na dança esportiva a execução da dança se dá a partir de um embasamento técnico que envolve a dança de salão competitiva.

É importante ressaltar que, para o corpo realizar certos movimentos na dança em cadeira de rodas, é necessário praticarmos uma determinada técnica. A técnica aqui é incluída como estrutura básica de movimentos que modula a postura corporal (FERREIRA, 2009). Nesse contexto, ela só é possível quando se concretiza a partir de princípios que possibilitam a configuração do corpo em determinadas formas posturais na relação forma/espaço dentro de um contexto coreográfico.

Portanto, para se entender a dança seja ela esportiva ou artística é necessário um embasamento teórico e prático que possibilite o entendimento dos movimentos corporais entre o casal. Em se tratando da AD desta modalidade existem algumas etapas que devem ser cumpridas, para que haja uma melhor compreensão das pessoas com deficiência visual ao apreciá-las.

Para a produção de uma AD de uma Dança em Cadeira de Rodas o audiodescritor deverá apresentar uma parte introdutória composta por: apresentação pessoal, descrição do espaço físico, apresentação dos bailarinos, sinopse do espetáculo da dança em cadeira de rodas e roteiro da coreografia.

Em relação ao espetáculo em si, ou melhor a coreografia, o audiodescritor deve apreciar os ensaios in loco ou em vídeo, no qual serão consultados coreógrafos e dançarinos 
sobre os termos utilizados na dança em cadeira de rodas, os quais são específicos do estilo e por isso, essa pesquisa propõe ao audiodescritor a familiarização com as nomenclaturas utilizadas na dança em cadeira de rodas, o que em muito facilitará o seu trabalho.

Para uma melhor compreensão sobre da $\mathrm{AD}$ na modalidade que este estudo se comprometeu a analisar - a DECR - no estilo Rumba - descrevemos o desenvolvimento da proposta e os métodos utilizamos para a produção e aplicabilidade deste recurso.

\section{A Criação da Proposta de AD em DECR - no estilo Rumba}

O estudo envolveu uma pesquisa de natureza descritiva, procurando analisar os principais movimentos de uma das coreografias de dança em cadeira de rodas - ritmo latino rumba apresentada pela dupla de dançarinos Bielorrussos Piotrecki Wanicki e Dorota Janowska.

Para descrever os principais movimentos da coreografia foi utilizado o software Workshop (SW), versão 2.51, desenvolvida pela UrusoftSubtlitles Workshop que é um dos softwares de legendagem mais simples e comumente utilizados. O uso desse programa permitiu marcar o início e o fim de cada inserção, enquanto inseria as unidades descritivas de um fragmento da dança em cadeira de rodas acessado no software. Esses dados foram transferidos para o processador de texto Word Office 2007 da Microsoft.

Em seguida, o roteiro foi organizado em uma tabela, contendo os seguintes elementos: número sequencial das descrições; tempo inicial e final conhecidos tecnicamente como: Time Code Reader (TCR), o qual se refere ao intervalo de tempo onde foram inseridas as linhas de texto da AD ou unidades descritivas; e o texto contendo as descrições elaboradas a partir do estudo das imagens.

Após o término da construção da $\mathrm{AD}$ da coreografia foi realizada um estudo de campo, de natureza exploratória, com a apresentação da AD a dois grupos de participantes sendo um grupo composto por 02 pessoas com deficiência visual denominados: P1 do sexo masculino com idade de 53 anos, com grau de escolarização superior, atua como procurador da Fazenda Nacional é deficiente visual congênito e tem experiência em dança de salão; P2, pessoa do sexo masculino, com nível superior atua como servidor público, têm 55 anos com deficiência visual congênita e não é familiarizado com a dança; e o outro grupo composto por pessoas da área de dança denominados P3 dançarino em cadeira de rodas, do sexo masculino, grau de escolaridade fundamental completo, têm 43 anos e conhece a técnica da modalidade; $\mathrm{P} 4$, do sexo feminino com nível superior, sua idade é 43 anos. Atua como assistente social e dançarina andante com experiência em dança de salão com cadeirantes.

Ao final da apresentação do vídeo escolhido com a narração em AD da dança em cadeira de rodas, todos responderam a um questionário sobre o significado e os sentidos da dança apresentada. Após responderem ao questionário, os participantes relataram por meio de uma entrevista focal seus entendimentos sobre $\mathrm{AD}$ apreciada, quanto ao significado/entendimento da coreografia. Por fim apresentaram suas opiniões sobre a compreensão dos gestos corporais narrados através da AD. Todos estes procedimentos foram analisados pela própria pesquisadora.

Cabe ressaltar que os aspectos éticos da pesquisa foram rigorosamente observados, de forma a atender a Resolução 196/96 do Conselho Nacional de Saúde, antes de participar da pesquisa, os entrevistados assinaram o termo de consentimento livre e esclarecido. 


\section{A AD de um espetáculo de dança em cadeira de rodas: relato de experiência}

De acordo com o conhecimento técnico sobre a DECR e juntamente com o recurso da AD utilizamos o Subtitle Workshop no qual foi elaborado um roteiro para audiodescrever o ritmo da rumba - uma das modalidades da dança esportiva que expressa nos seus movimentos uma história de amor romântica e sensual. A Figura 1 mostra como o programa funciona.

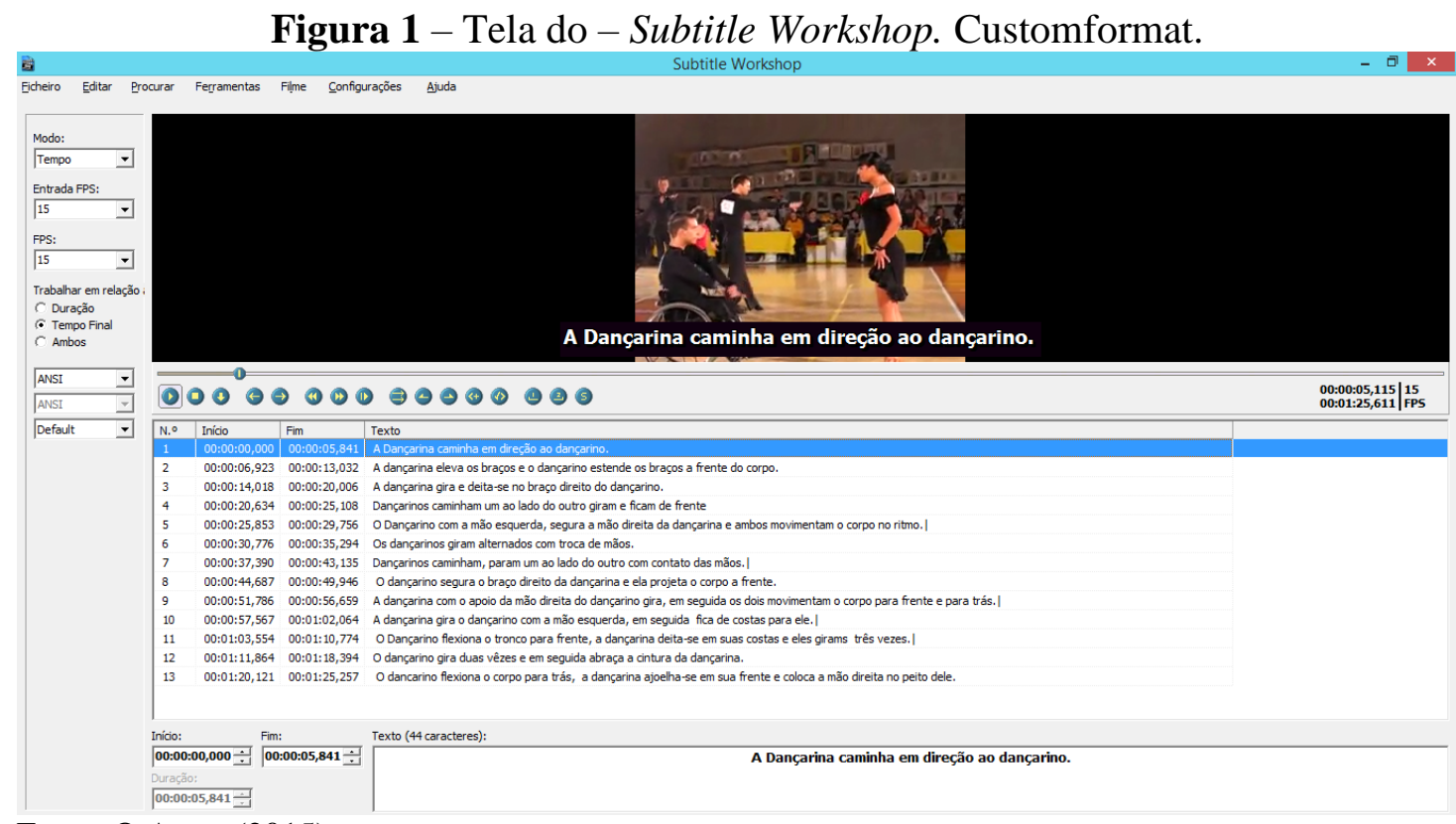

Fonte: O Autor (2015).

A Figura 1 mostra os dois dançarinos em uma competição de dança esportiva em cadeira de rodas. O programa resulta em um arquivo de texto no formato word com a lista de descrições da AD. O arquivo foi salvo no formato Adobe Encore DVD, pois este apresenta, além dos tempos iniciais e finais, os frames dos momentos exatos do filme em que as descrições devem ocorrer.

Na marcação 1 é identificado onde o filme está sendo apreciado. A câmara focaliza os dançarinos de perfil um de frente para o outro. Esta cena começa no tempo 00:00:01,180(00 horas, 00 minutos, 01 segundos e 180 frames) e vai até 00:00:07,340 (00horas, 00 minutos, 07 segundos e 340 frames) quando a cena é então cortada para focalizar a próxima. A AD desse trecho tem a seguinte exposição: "A dançarina com vestido preto justo vai em direção a dançarino cadeirante, sobe o vestido, mostrando as coxas, eleva os braços".

O tempo total da cena é equilibrado com o tempo total da descrição. Quando há mais elementos e esses não dão para serem descritos em tempo suficiente, o audiodescritor pode optar por não descrevê-los, fazendo a seleção das informações mais relevantes para que a pessoa com deficiência visual possa entender o contexto e também ouvir a trilha sonora.

O Subtitle Workshop mostrou-se um programa eficiente para a elaboração do roteiro da $\mathrm{AD}$, pois permitiu visualizar a dança, o que facilitou a descrição dos elementos visuais. 
Além disso, o arquivo gerado por ele permitiu que os tempos exatos da narração fossem inseridos, auxiliando o narrador e a gravação final do áudio.

A legenda seguiu o fluxo da coreografia que a partir das execuções das frases musicais nos permitiu concretizar a descrição primeiramente dos bailarinos:

Piotrecki Iwanick é um homem cadeirante de pele clara, cabelos curtos e pretos. Usa camisa preta de mangas compridas colada ao corpo entreaberta no peito, calça e sapatos pretos. Nas costas, uma placa branca, com um número.

Dorota Janowaska é mulher de pele clara, alta, de cabelos pretos presos em coque, com franja. Usa vestido preto justo, na altura dos joelhos, com babados no decote e barra, com ombros e pernas a mostra, e uma rosa vermelha no decote. Usa sandálias de salto alto douradas.

Logo após foi elaborado o roteiro para a descrição do espaço e do estilo de dança que iria ser executada:

O vídeo apresenta trecho de dança esportiva em cadeira de rodas, praticado por um casal de dançarinos, sendo que o dançarino é cadeirante e a dançarina andante.

O ritmo aqui apresentado é a rumba, que expressa uma história de amor, romântica e sensual.

A apresentação de dança acontece em salão bem iluminado com piso em madeira, com várias fotos na parede, mesa comprido, onde árbitros estão sentados em volta da pista de dança. Vários casais estão dançando no sentido anti-horário e o casal mencionado é o destaque do salão. Pessoas assistem em torno do salão.

Após a elaboração do roteiro de AD sobre os bailarinos, do espaço e do tipo de dança que seria apresentada, iniciamos a proposta da $\mathrm{AD}$ do espetáculo, como podemos verificar no Quadro 1.

Quadro 1 - Roteiro da AD da dança em cadeira de rodas - modalidade rumba.

\begin{tabular}{|c|l|}
\hline MINUTAGEM & \multicolumn{1}{|c|}{ PROPOSTA DE AD } \\
\hline $\begin{array}{l}\text { 00:00:01,180-- } \\
>00: 00: 07,340\end{array}$ & $\begin{array}{l}\text { A dançarina com vestido preto justo vai em direção a Piotreck, sobe o vestido, } \\
\text { mostrando as coxas, eleva os braços }\end{array}$ \\
\hline $\begin{array}{l}\text { 00:00:08,244-- } \\
>00: 00: 10,552\end{array}$ & Ela balança os quadris, ele estende os braços. \\
\hline $\begin{array}{l}\text { 00:00:11,578-- } \\
>00: 00: 16,796\end{array}$ & Dorota gira suavemente e deita-se no braço direito de Piotreck. \\
\hline $\begin{array}{l}\text { 00:00:18,403-- } \\
>00: 00: 24,615\end{array}$ & Eles caminham lado a lado giram e olham-se profundamente. \\
\hline $\begin{array}{l}\text { 00:00:26,370-- } \\
>00: 00: 29,731\end{array}$ & Ela balança os quadris sinuosamente enquanto ele segura sua mão direita. \\
\hline $\begin{array}{l}00: 00: 30,902-- \\
>00: 00: 34,044\end{array}$ & Eles trocam as mãos enquanto giram alternados. \\
\hline $\begin{array}{l}00: 00: 34,648-- \\
>00: 00: 37,216\end{array}$ & Ela desce o corpo suavemente e acaricia o rosto dele. \\
\hline $\begin{array}{l}00: 00: 37,251-- \\
>00: 00: 38,978\end{array}$ & Eles se afastam de costas, ela caminha rebolando. \\
\hline $\begin{array}{l}00: 00: 39,663-- \\
>00: 00: 42,035\end{array}$ & Eles se aproximam sensualmente e passam um pelo outro. \\
\hline
\end{tabular}




\begin{tabular}{|l|l|}
\hline $\begin{array}{l}\text { 00:00:42,806-- } \\
>00: 00: 49,060\end{array}$ & Ele segura o braço direito de Dorota, enquanto ela desliza seu corpo para frente. \\
\hline $\begin{array}{l}\text { 00:00:50,306-- } \\
>00: 00: 53,292\end{array}$ & Dorota com uma perna gira o corpo com o apoio da mão direita de Piotreck. \\
\hline $\begin{array}{l}\text { 00:00:53,327-- } \\
>00: 00: 56,021\end{array}$ & Eles com contato das mãos jogam o corpo para frente e para trás. \\
\hline $\begin{array}{l}\text { 00:00:57,221-- } \\
>00: 00: 59,884\end{array}$ & As mãos deles se tocam. Braços e corpo dançam ondulantes. \\
\hline $\begin{array}{l}\text { 00:01:00,382-- } \\
>00: 01: 01,890\end{array}$ & Ele gira com o apoio da mão esquerda dela. \\
\hline $\begin{array}{l}00: 01: 03,111-- \\
>00: 01: 12,181\end{array}$ & $\begin{array}{l}\text { Ele estende o troco à frente. Ela deita-se sobre as costas dele, com uma perna } \\
\text { dobrada, a outra esticada. Eles giram três vezes. }\end{array}$ \\
\hline $\begin{array}{l}\text { 00:01:13,348-- } \\
>00: 01: 19,895\end{array}$ & Ele gira duas vezes e desliza suas mãos na cintura dela \\
\hline $\begin{array}{l}\text { 00:01:20,981-- } \\
>00: 01: 25,611\end{array}$ & Ele inclina o corpo para trás, ela ajoelha-se. \\
\hline
\end{tabular}

Fonte - O Autor (2015).

Diante do contexto, nosso estudo corrobora com Motta e Romeu Filho (2010) o qual enfatiza que a Audiodescrição se comporta como recurso de acessibilidade transferindo a dimensão visual de um espetáculo para o verbal, por meio de informações sonoras, ampliando, desta forma, o entendimento e promovendo o acesso á informação e à cultura. Sendo assim, à $\mathrm{AD}$ é uma ferramenta que auxilia no entendimento subjetivo de cada pessoa, sobre o sentido que este dá ao objeto/sujeito/espaço que está sendo descrito, como podemos identificar na fala de P1:

"Diante da AD, que assisti hoje, passei a ter uma impressão completamente diferente da dança em cadeira de rodas. Não imaginava que um cadeirante tivesse tanta agilidade. A AD permitiu que uma pessoa com cegueira total, possa ter acesso a detalhes da dança. Nota-se que, aquilo que, sem $\mathrm{AD}$, não tinha graça nenhuma para a pessoa com cegueira, com ela a dança passa a ser um espetáculo verdadeiramente belo".

O recurso visa a quebra de paradigmas diante a inserção do deficiente visual em ações culturais, a partir deste recurso torna-se possível a convivência e a participação do mesmo não só neste meio, mas também, em um melhor convívio social. Nesse contexto, é importante ressaltar a opinião de $\mathrm{P} 2$, que ao deparar-se com a dança em cadeira de rodas pela primeira vez se surpreende com tal fato:

"Sempre tive dificuldade em assistir apresentações de dança em cadeira de rodas, pois não entendia o que estava acontecendo. Hoje, pela primeira vez, embora de forma rápida eu pude ouvir à $\mathrm{AD}$ de uma dança o que para mim foi novidade, por não ser um campo de muito domínio. O que ouvi me satisfez".

Por este mesmo contexto P3 considera a proposta de AD apresentada como satisfatória para a compreensão da dança em cadeira de rodas para pessoas com e sem deficiência: 
"Diante da minha experiência em dança em cadeira de rodas foi possível entender toda a descrição dos movimentos corporais dos dançarinos. Para mim, ficou bastante claro, a necessidade da AD para a integração cultural da pessoa com deficiência visual. Com a utilização da AD é possível compreender os elementos da dança em cadeira de rodas, bem como, participar de todos os tipos de apresentações culturais".

Já para $\mathrm{P} 4$, os movimentos apresentados na dança em cadeira de rodas através da AD tiveram a seguinte conotação:

“A AD para mim vem como um marco, visando dentro de uma proposta de inclusão social elencar e proporcionar as pessoas com cegueira conseguir sentir de forma plena o movimento do corpo na dança.”.

Como diz Ferreira (2003) a dança só tem sentido por quem a dança, porque este estabelece relações de sentido com o seu corpo, com o espaço e com o outro. Na AD a apreensão desse sentido deve ser feita por quem está apreciando a narração, a qual deve ser preenchida, também, com palavras que façam com que o deficiente visual, pela sua própria experiência de vida possa buscar subsídios para entender o contexto da trama que ali esteja acontecendo.

Enfim, o que podemos analisar pelos depoimentos dos participantes e pela entrevista que a proposta da $\mathrm{AD}$ apresentada neste estudo foi satisfatória para o entendimento dos movimentos e dos sentidos que os bailarinos quiseram dar à coreografia, não necessitando de grandes ajustes ao roteiro pré-estabelecido. Outro fator que merece destaque e muito mencionado, também, pelos participantes é que a $\mathrm{AD}$ é um recurso relevante e significativo para o processo da inclusão sociocultural das pessoas com deficiência visual. Portanto, o contato e a familiarização com as nomenclaturas da dança em cadeira de rodas aqui expostas ampliaram o conhecimento e a vivência dessas pessoas em relação a esta modalidade de dança, além de trazer subsídios importantes para que o audiodescritor.

\section{CONSIDERAÇÕES FINAIS}

A AD é o recurso de acessibilidade comunicacional que faz a pessoa com deficiência visual conhecer e mergulhar no universo fascinante das imagens. Nesta perspectiva, o que pudemos analisar, pela construção e apreciação de uma proposta de AD a um estilo de dança em cadeira de rodas - A Rumba, é que este mecanismo trouxe maiores oportunidades de entendimento sobre a dança executada e um outro sentido àquilo que está sendo descrito.

Dessa forma, no que se refere a descrição de movimentos de dança em cadeira de rodas, a $\mathrm{AD}$ vem viabilizar oportunidades de comunicação, nas quais a estética visual torna-se mais uma referência no processo de formação dos indivíduos. Isto porque é capaz de projetar uma dança internamente cheia de sensações e sentimentos que as pessoas videntes ou não videntes são levadas a perceber.

É importante salientar que, a aplicação da proposta de AD, no estilo Rumba em DECR, constitui-se ser um grande desafio, pois, devido ao seu ritmo rápido, há pouco tempo de execução entre um movimento e outro, assim, o audiodescritor precisa ter a sutileza e percepção do todo para fazer suas escolhas. É necessário incluir leveza na escolha das palavras, musicalidade na voz, que narra os movimentos e conhecimento de termos técnicos 
para traduzir os passos. A proposta aqui apresentada pode ainda servir como base para a AD dos demais ritmos da DECR e como referência para demais estilos de dança.

Enfim, inferimos para futuras pesquisas explorar a efetividade das descrições aqui apresentadas para a compreensão dos movimentos da dança para pessoas com deficiência visual em diferentes contextos, desde os processos ensino-aprendizagem da dança até a apresentação e veiculação de espetáculos em DECR, permitindo que esta modalidade de dança, por meio da AD seja acessível ao deficiente visual em futuras competições nacionais e internacionais.

\section{REFERÊNCIAS}

ANJOS, D. R. Abordagens para atividades físicas e esportivas inclusivas para pessoas com deficiência visuais. In: FERREIRA, Eliana Lucia (Org.). Atividade física, deficiência e inclusão escolar. Niterói: Intertexto, 2010. v. 3.

BENECKE, B. Audio-description. In: GAMBIER,Y. (Ed.). Traduction audiovisuelle/Audiovisual Trasation. Meta, Les Presses de I'UniversitéLocal,v. 49, n.1, Apr. 2004, p. 78-80. Disponível em:

<http://www.erudit.org/revue/meta/2004/v49/n1/009022ar.html>. Acesso em: 13 abr. 2010.

BRASIL. Lei $\mathrm{n}^{\circ} 10.098$, de 19 de dezembro de 2000. Estabelece normas gerais e critérios básicos para a promoção da acessibilidade das pessoas portadoras de deficiência ou com mobilidade reduzida, e dá outras providências. Diário Oficial [da] República Federativa do Brasil, Brasília, DF, p. 2-3, 20 dez. 2000. Disponível em:

<http://portal.mec.gov.br/arquivos/pdf/lei10098.pdf>. Acesso em: 9 abr. 2010.

BRASIL. Ministério das Comunicações. Portaria n ${ }^{0}$ 310, de 27 de junho de 2006. Recursos de acessibilidade, para pessoas com deficiência, na programação veiculada nos serviços de radiodifusão de sons e imagens e de retransmissão de televisão. Diário Oficial da União, Brasília, DF, p. 5, jan. 2006. Disponível em:

<http://www.erudit.org/revue/meta/2004/v49/n1/009022ar.html>. Acesso em: 13 abr. 2010.

BRASIL. Ministério das Comunicações. Portaria n. 466, de 30 de julho de 2008. Concede o prazo de noventa dias, para que exploradoras de serviço de radiodifusão de sons e imagens e de serviço de retransmissão de televisão (RTV) passem a veicular, recurso de acessibilidade. Diário Oficial da União, Brasília, DF, p. 5, 3 jul. 2008. Seção 1.Disponível em:

<http://www.erudit.org/revue/meta/2004/v49/n1/009022ar.html>. Acesso em: 13 abr. 2010.

FERREIRA, E. L. Práticas corporais inclusivas. In: FERREIRA, Eliana Lucia (Org.). Esportes e atividades físicas inclusivas. Niterói: Intertexto, 2009. 
FERREIRA, E. L. Corpo-movimento-deficiência: as formas dos discursos da/na dança em cadeira de rodas e seus processos de significação. Tese (doutorado) - Universidade Estadual de Campinas, Faculdade de Educação Física, 2003.

FRANCO, E. P. C.; SILVA, M. C. C. C. Audiodescrição: breve passeio histórico. In: MOTTA, Lívia M. V.; ROMEU FILHO, Paulo (Org.). Audiodescrição: transformando imagens em palavras. São Paulo: Secretaria dos Direitos da pessoa com Deficiência do Estado de São Paulo, 2010.

HOFFMANN, Sonia B. Benefícios da orientação e mobilidade: estudo intercultural entre Brasil e Portugal. In: Revista Benjamin Constant, Rio de Janeiro, ano 5, n. 14, p. 11-16, 1999. Disponível em: http://www.ibc.gov.br/?catid=4\&itemid=56. Acesso em: 17 jul.2015.

INSTITUTO BRASILEIRO DE GEOGRAFIA E ESTATÍSTICA- IBGE. CENSO 2010. Disponível: <https://censo2010.ibge.gov.br/> . Acesso em 28 de maio de 2015.

JAKOBSON, R. Aspectos linguísticos da tradução. Tradução Izidoro Blikstein. In: JAKOBSON, R. Lingüística e comunicação. São Paulo: Cultrix, 1995. p. 63-86.

MAZZOTA, M. J. S. Educação Especial no Brasil: história e políticas públicas. São Paulo: Cortez, 2005.

MENDONÇA, Alberto et al. Alunos cegos e com baixa visão: orientações curriculares. 2008. Disponível em: <http://www.deficienciavisual.pt/x-txt-aba-

OrientacoesCurricularesCegosBxV.pdf>. Acesso em: 14 nov. 2012.

MOTTA, L. M. V.; ROMEU FILHO, P. (Org.). Audiodescrição: transformando imagens em palavras. São Paulo: Secretaria dos Direitos da pessoa com Deficiência do Estado de São Paulo, 2010.

Recebido em: 17/10/2019

Aprovado em: 08/12/2019 